\title{
Validation of a urine metabolome fingerprint in dog for phenotypic classification
}

\author{
Mark R. Viant - Christian Ludwig • \\ Sue Rhodes · Ulrich L. Günther · David Allaway
}

Published online: 11 November 2009

(C) Springer Science+Business Media, LLC 2009

\section{Erratum to: Metabolomics (2007) 3(4):453-463 \\ DOI 10.1007/s11306-007-0092-0}

In the paper entitled: "Validation of a urine metabolome fingerprint in dog for phenotypic classification" published in the December 2007 issue; 3(4): 453-463, the authors erroneously stated that the dogs were all neutered. Records have shown that two of the dogs were entire (MS2 \& MS3, samples 23-32). This error has made no impact on the interpretation of the data and re-analysis of the data provides no more meaningful interpretation. PCA plots indicate that these two dogs are not outliers, which suggests that "sex status" is not a major driver of variance in this study.
The online version of the original article can be found under doi:10.1007/s11306-007-0092-0.

M. R. Viant ( $\square)$

School of Biosciences, University of Birmingham, Edgbaston,

Birmingham B15 2TT, UK

e-mail: M.Viant@bham.ac.uk

C. Ludwig · S. Rhodes · U. L. Günther

Henry Wellcome Building for Biomolecular NMR Spectroscopy,

Division of Cancer Studies, University of Birmingham,

Edgbaston, Birmingham B15 2TT, UK

D. Allaway

WALTHAM Centre for Pet Nutrition, Freeby Lane, Waltham-

on-the-Wolds, Melton Mowbray, Leicestershire LE14 4RT, UK 